\title{
Escribir, traducir y componer: usos de la literatura en la música
}

\author{
Jorge Fondebrider ${ }^{\bullet}$
}

En 1876, el poeta Stéphane Mallarmé publicó su poema "L'Après-midi d'un faune", una égloga de ciento diez alejandrinos, en la que la criatura mitológica evoca a las ninfas y a la naturaleza, en lo que, simbólicamente, podría pensarse como el crepúsculo de su vida. Acompañado en la ocasión por ilustraciones de Édouard Manet —uno de los mejores amigos de Mallarmé-, el texto tuvo un éxito casi inmediato y una transfiguración que lo vuelve pertinente para abordar las relaciones que existen entre distintos lenguajes artísticos.

En 1890 Mallarmé, ya por entonces jefe indiscutido de la escuela simbolista aunque astutamente decía que ese honor le correspondía a Paul Verlaine-, le pidió a Claude Debussy que escribiera una música incidental que pudiera preceder y acaso seguir a la recitación del poema. Dos años después, Debussy —uno de los muchos admiradores del poeta y, desde 1887, frecuente visitante de las tertulias que tenían lugar en la casa de la 89 rue de Rome, todos los martes, de octubre a mayo, entre las 16 y las 19- esbozó un Prélude, interludes et paraphrase finale pour l'après-midi d'un faune, que más adelante se acortó a Prélude à l'après-midi d’un faune. Según nos hace saber Gustave Doret, quien dirigió su estreno en la Societé Nationale el 22 de diciembre de 1894, la pieza fue un rotundo éxito y le significó a Debussy convertirse en un compositor respetado por sus pares y por el público. El mismo Mallarmé se manifestó muy contento y expresó su alegría en unos virtuosos versos laudatorios más bien triviales, que sólo la circunstancia saca

\footnotetext{
- Poeta, ensayista, traductor y periodista cultural y colaboró con los principales diarios y revistas nacionales. Entre 1986 y 1992 fue secretario de redacción de la revista Diario de Poesía e integró su consejo de dirección. Desde el 2002 hasta 2006 se desempeñó como coordinador de eventos y publicaciones del Centro Cultural Ricardo Rojas de la UBA. En 2009, junto con Julia Benseñor, creó el Club de Traductores Literarios de Buenos Aires.

A la fecha, tiene publicados siete libros de poesía, compiló y editó otros 13 y es autor de otros siete libros de ensayos. Como traductor del inglés y del francés, ha publicado 27 trabajos. Con Gerardo Gambolini publicó la antología bilingüe Poesía irlandesa contemporánea (Buenos Aires, Libros de Tierra Firme, 1999) y otras traducciones de poesía angloescocesa, popular irlandesa y de poetas modernos. De la última producción se destacan La París de los argentinos (Buenos Aires, Bajo la Luna, 2010); Música y poesía (México D.F., UNAM/CONACULTA, 2014) e Historia de los hombres lobo (Santiago de Chile, LOM, 2015 / Buenos Aires, LOM, 2016). El trabajo que incluimos es parte del libro publicado en México en 2014 y contiene desarrollos brindados durante su visita el día 10 de junio de 2016, a la sede de la FHUC-UNL invitado por el Departamento de Letras.
} 
del olvido. Quizás el entusiasmo del poeta se debiera menos a la obra en sí que a lo que interpretó como un acercamiento al ideal wagneriano, al cual ya le había dedicado un artículo celebratorio en 1885, afirmando tiempo después, en 1894, que «Desde Wagner, la música se une al verso para formar la poesía». Lo curioso es que Mallarmé, como muchos de sus contemporáneos wagnerianos, nunca había escuchado a Wagner. Pero ésa es otra historia.

Ahora bien, volviendo a Debussy, interesa mencionar que la partitura original de su obra incluía el siguiente texto: «La música de este Prélude es una ilustración muy libre de un bello poema de Mallarmé; no pretende ser una síntesis de éste. Se trata más bien de fondos sucesivos sobre los cuales se mueven los deseos y los sueños de un fauno al calor de esa tarde». Aparentemente los reparos de Debussy estarían ligados a un episodio algo anterior, al que, a falta de mayores precisiones, podríamos considerar apócrifo.

Debussy, como la mayor parte de los compositores de su tiempo, en los estertores del movimiento romántico — del cual tanto el simbolismo como el impresionismo son tardíos tributarios_- estaba muy interesado en musicalizar poemas. Se sirvió así de textos debidos a poetas del pasado (Charles d'Orléans, François Villón), y también de lo que escribían sus contemporáneos (Charles Baudelaire, Paul Verlaine, Leconte de Lisle, Théophile Gautier, Pierre Louÿs, etc.). En total, compuso cerca de 80 canciones para voz y piano. $Y$ en algún momento, quiso hacer lo mismo con los poemas de Mallarmé. Según la tradición, el compositor, lleno de entusiasmo, en cierta oportunidad se habría dirigido al poeta para hacerle saber que le había puesto música a unos poemas suyos. Mallarmé, reputado como uno de los mayores técnicos de todos los tiempos, parece haberle contestado a Debussy: «Yo creí que ya tenían música». De haber ocurrido esto, habría tenido razón, pero, con Victor Hugo y Gerard de Nerval, habría pasado a integrar el panteón de los poetas que hicieron explícito su rechazo a que los compositores trabajaran sobre sus poemas. Pero Debussy, que persistió en su propósito, como se verá más adelante, también tuvo razón.

Volviendo entonces al Prélude à l'après-midi d'un faune, las cosas podrían haberse complicado aún más, dado que la pieza de Debussy a su vez dio origen a L'Après-midi d'un faune, coreografía creada en 1912 por Vaslav Nijinski, quien recupera esta vez el nombre del poema original, del que sólo es deudor en segunda instancia. Mallarmé no llegó a enterarse: murió en 1898.

Hasta aquí, por un lado, hay un poema sobre el que se escribe una música incidental, la cual sirve como posterior excusa para una coreografía. Pero, por el otro, unos textos que no sólo son inspiradores de una obra, sino que se vuelven parte integrante de la obra. Entonces, ¿qué sucede cuando un texto pierde su autonomía para convertirse en un elemento entre otros elementos que componen una obra? No hay una única respuesta.

Cuando en 1913, sirviéndose de «Soupir», «Placet futiles» y «Éventail», Debussy compuso finalmente sus Trois poemes de Mallarmé, es de suponer que tenía ya una práctica importante en emplear poemas como materiales para la composición de canciones. En otras palabras, con o sin la complacencia del poeta, sabía plenamente lo que hacía, que es lo que desde siempre venían haciendo todos los compositores cuando trabajaban sobre un texto: desplazar acentos, alargar cantidades, repetir o suprimir palabras. Todas esas operaciones, de naturaleza más bien técnica, a los efectos estéticos e ideológicos se verifican en interpretaciones, revaluaciones, énfasis y eclipsamientos. El crítico George Steiner, en su monumental Después de 
Babel. Aspectos del lenguaje y la traducción, señala que esos procedimientos bien pueden asimilarse al trabajo de un traductor. Promediando su texto $-\mathrm{y}$ con toda pertinencia respecto de la cuestión que nos ocupa-, Steiner se pregunta hasta qué punto la cultura es la traducción y reformulación de una significación anterior. Para responderse, toma como ejemplo la transmutación de los textos poéticos en partituras musicales. Señala entonces: «El compositor que pone música a un texto está inscrito en la misma secuencia de movimientos intuitivos y técnicos que se plantean en la traducción propiamente dicha. Su confianza inicial en la significación del sistema de signos verbales va seguida de una apropiación interpretativa, de una 'transferencia' a la matriz musical y, por último, de la elaboración de un nuevo todo, que ni devalúa ni eclipsa a la fuente lingüística». Y añade: «La prueba de la inteligencia crítica, de sensibilidad psicológica, a la que se somete el compositor cuando elige un poema, lo dispone y le pone música, concuerda en todo con la del traductor. En ambos casos preguntamos: ¿ Ha entendido el argumento, el tono emocional, las particularidades formales, las convenciones históricas, las ambigüedades potenciales del original? Ha sabido encontrar el medio idóneo para representar cabal y explícitamente esos elementos?». Steiner concluye: «Los recursos que están a mano del compositor - tonalidad, timbre, tempo, ritmo, instrumentación, modo- corresponden a las opciones estilísticas abiertas para el traductor».

A pesar de las numerosas evidencias de que la asociación entre poesía y música se ha dado desde siempre, los ejemplos de Steiner corresponden casi todos al siglo XIX, momento en esa tendencia se profundiza porque, de acuerdo con Gerald Abraham, durante el prolongado período estético denominado Romanticismo la literatura precede a todas las otras disciplinas artísticas. Así, «la vocación literaria de los compositores fue lo que los hizo románticos: dondequiera que mirasen en la literatura contemporánea, encontraban literatura romántica». En consecuencia, los textos de base corresponden a grandes escritores, como Goethe, Schiller, Heine, Hoffmann o Chamizo, pero también a otros más limitados como Eduard Mörike o Wilhelm Müller, a los que sólo el talento de Hugo Wolf, en sus Lieder, o de Robert Schumann, en Die Winterreise, salvan del completo olvido. Y dado que el Romanticismo no debe entenderse en bloque, sino atendiendo a los momentos y características nacionales de cada uno de los lugares donde se manifestó, lo ocurrido en Alemania — cronológicamente, la primera en manifestar los síntomas de cambio respecto de los estilos anteriores-, también se dio en Inglaterra, Francia, Italia, Rusia y las áreas de influencia de cada uno de estos países. Con el correr del tiempo, prácticamente toda la poesía — considerada aquí como mero materialfue susceptible de convertirse en otra cosa, tendencia que, para el siglo XX se había convertido sin discusión en un modus operandi absolutamente normal.

Con relación a la ópera —acaso la culminación de las distintas formas dramático-musicales-, puede decirse que el derrotero seguido por las dramaturgias y los textos narrativos es muy similar al recorrido por los textos poéticos. A los desplazamientos acentuales y a las otras variaciones técnicas antes aludidas se agregan, no obstante, otras de naturaleza meramente dramática porque en este caso hay una forma asimilable al relato que se canta, desarrollándose a través de escenas que se actúan, sumando así a la partitura y a su posible interpretación por parte del director de orquesta, la doble interpretación del regisseur y la del cantante. Dicho de otro modo, Benjamín Britten — con su utilización de Herman Melville, Henry James o Thomas Mann, probablemente uno de los compositores contemporáneos más 
sensibles a la literatura-, no tiene reparos en reducir el número de actos y personajes en su ópera Midsummer Night's Dream, respecto del original de Shakespeare, y probablemente los numerosos directores y puestistas de esa obra tampoco han tenido reparos en proceder a voluntad respecto de la partitura de Britten. Como señalaba Steiner, uno y otro están traduciendo y reformulando una significación anterior. Y aunque les pese a los puristas, así funcionó siempre la cultura.

\section{Fondebrider, Jorge}

«Escribir, traducir y componer: usos de la literatura en la música». El hilo de la fábula. Revista anual del Centro de Estudios Comparados (16), 201-203. 


\section{Seis,}

testimonios tangibles

(un lugar para el convivio) 